\title{
The History and Evolution of Kinetic Art
}

\author{
Guang-Dah Chen, Chih-Wei Lin, and Hsi-Wen Fan
}

\begin{abstract}
Kinetic Art is a model of dynamic perceivable expression. As the continuous advance and improvement of science and technology, Kinetic Art thus combined with the technology of each year and displayed different appearances that it has been deeply influenced by technology and its development. This research would investigate the history of Kinetic Art via reviewing literature. And discuss the expression appearance in each stage and the influence on current Kinetic Art. Finally, the following viewpoints are proposed. 1. The evolution of Kinetic Art are gradually turned from living entertainment to art fields, and has a tight connection with technology. 2. Bauhaus established the position of Kinetic Art in the education of plastic design, and Kinetic Art is the indispensable manifestation pattern in the education of design. 3. Technology exists inside the creative ideas of Kinetic Art and that will drive the development of new fields of vision. 4. Kinetic Art will be conducted by high-tech and sustainably precede development of dynamic optical illusion effect and combine interaction and participation.
\end{abstract}

Index Terms-Design education, interactive art, kinetic art, mechanical music instruments.

\section{INTRODUCTION}

Kinetic arts could be divided into 2 categories. The first category refers to the shaping with actual motion. The other one category is that the shaping is stationary but would form illusion phenomenon in motion perception on the retina. The kinetic art before the 20th century mainly aimed to create a more convenient and efficient lifestyle. After the 20th century, the products of modern industrial technology (i.e., new machinery, tools, and materials) kept being developed, and the once entertainment-oriented kinetic art designing moved towards the field of art. This very shift provided a new opportunity and energy of art. Thus, it developed into one artistic school and named as kinetic art.

In addition, forward-looking Bauhaus incorporated kinetic art and relevant basic science into the curriculum of preparatory education. Except for the announcement that kinetic art must combine scientific knowledge and technology, kinetic art started to become the research focus and direction of design element, laying the foundations for future design education of kinetic art. As the wheel of time turns, the source of power is not limited to solely machines

Manuscript received June 11, 2014; revised August 15, 2014. The authors would like to express their thanks to the Ministry of Science and Technology, Taiwan, R.O.C., who have sponsored the research presented in this paper under Grant MOST 103-2410-H-224-030-

Guang-Dah Chen and Hsi-Wen Fan is with the Department of Digital Media Design of the National University of Science and Technology, Yunlin, Taiwan (e-mail: gd196478@yahoo.com.tw, tncelny30061991@ hotmail.co $\mathrm{m})$.

Chih-Wei Lin is with the Graduate School of Design of the National University of Science and Technology, Yunlin, Taiwan (e-mail: copy1.copy2@msa.hinet.net). since electronic technology and digital technology are all involved. And on the back of power, it is also supported by theoretical basis. The aforementioned information sufficiently proves that in an environment where technology gradually flourishes, the development and concepts of kinetic art progress and evolve accordingly, and there has been a gradual integration and fusion of between kinetic art and technology. Therefore, the current study focused on time and analyzed the development and progress related to kinetic art in each stage. In addition to the roles that technology and technique played in kinetic art, the current study explored the developmental context and evolvement of kinetic art, with the aim to ascertain the value of kinetic art in designing and plastic arts.

\section{DeVelopment of Kinetic ARt Before 20th Century}

\section{A. The Beginning of the Infancy of Kinetic Art}

In 1897 , the mural art about jumping cattle drawn by ancient people 20-30 thousand years ago was found in the grotto cave in Cantabrian, France. The amazing streamlined approach vividly capture the pace and dynamic extracts of the animals, which could serve as the proof that they concerned about the dynamic things. In the ancient ceremony of Osiris in Egypt, one doll (Fig. 1) with height about 50 centimeters that could be pulled by a string was found. Then in the ancient tomb coffin in Memphis, and etc., many dolls with movable shoulders and foot joints were also found. These dolls take advantage of the towing and dragging of string to produce motions. In addition to the joints of hands and legs, the arms of these dolls could also do simple up-and-down motion [1].

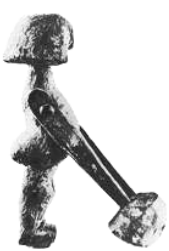

Fig. 1. Ancient Egypt Doll [2].

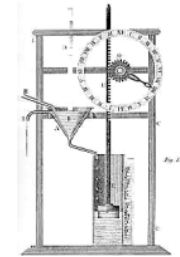

Fig. 2. Water clock [3].
Greek inventor Ctesibius (B.C.285-222) designed water clock, which underwent accurate control on water flow through numerous pistons. This could serve as the driving force for numerous automatic devices including bells, marionettes, and songbirds (Fig. 2). Another inventor, Philon (B.C.280-220), Byzantium scientist, invented "ink pot", an eight-sided ink pot with an opening on each side could be turn so that any face is on top, dip in a pen and ink it-yet the ink never runs out through the holes of the side according to the principles of gimbals. 
In the 2nd century BC, Greek architect built a statue that floats in the air for the wife of Egyptian King Ptolemy II (B.C.284-246). The floating structure was dependent on the overall setting of magnetic forces on the roof and wall [4]. It seems that such technology of magnetic force application does not exist anymore. From the literatures described above, it could be realized that people in early time periods already knew how to take advantage of various scientific principles to design machines and tools or artistic expression. No matter whether these inventions were functional, they are all wonderful masterpieces.

Heron of Alexandria was a genius inventor that advocated and promoted the invention described above. He not merely took advantage of power sources such as wind power, water flow, fire, and pressure-driving force to improve organs. In addition to actively invent the first steamer, he also designed automatic devices such as mechanical puppet theater, fire engines, milestones meter, and measuring instrument similar to modern theodolite. He also invented automatic devices such as automatic holy water devices, automatic nectar supply devices, steam power balls, and automatic organ systems [4]. It is amazing that one person in the 1st century could own such striking technology and thoughts.

According to the records of the literatures described above, it could be known that people had abundant imagination and creativity on the moving things and motion itself since ancient times. It also could be found that people attempted to take advantage of various mechanic powers to produce actual motion effects for creating more convenient living methods as well as elevating working efficiency and recreational functions in very early time.

\section{B. Kinetic Art from Tradition to Modern}

In the middle ages, Europe was an enclosed society. There were few development and elevation of related technology within that time period of about 1000 years. It was not until the $14^{\text {th }}$ century that "Renaissance" rose in Da interest Florens Adams did the science and art highly break through.

Mechanical music instruments started to prevail in the middle ages. For the kinetic shaping aspect, it is a concrete characterization that totally integrates "technology" into daily life. It is also a novel expression for the development of kinetic shaping. The first automatic instrument was a clock configured with chimes and the pushing of steelyard weights. This device took advantage of the mechanical principles to roll a metal cylinder covered with pegs to beat the chimes, which allows the instruments to play different tunes.

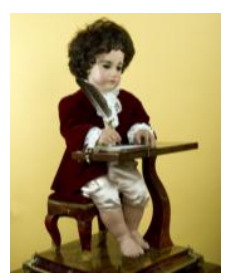

Fig. 3. Pierre Jaquet Droz, the writer, 1768 [5].

The propulsion not only took advantage of wind but also took advantage of the power produced by paddle wheel to play music. The development of new technology allowed people to take advantage of the smaller water flows to push the mechanics. Such technology significantly minimized the huge volumes of automatic organs and chime. Pierre Jaquet Droz (A.D.1721-1790), a Swiss, invented 3 Jaquet-Droz Automaton (Fig. 3) that could do the writing, painting, and music playing works within the time period from 1768 to 1774. This was the earliest device that could operate the automatic procedures via precise mechanical elements and structures. This could be regarded as the ancestor for the following automatic control, modern mechanical calculators, and the early electronic calculator.

In 1738, Jacques de Vaucanson (A.D.1709-1782), a French person, invented flute player. The most famous work of James Cox (A.D.1723-1800), a British person, was a golden and huge Peacock Clock designed for Catherine II in 1772. Pedro Pierre Jacques, Jacques Buddha Gan Johnson, and James Cox were all very famous watch artisans at that time. All of the artistic boutiques were exported to China, India, and other Far East regions.

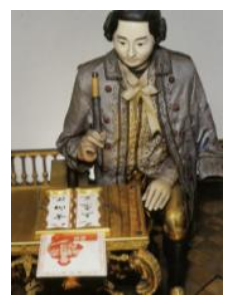

Fig. 4. Copper-plated gold writing automaton, 1770 [6].

In 1770 , British minister gave a writing automaton to Qianlong, the emperor of Chinese Qing Dynasty. This writing automaton could use writing brush to write 8 Chinese characters: Ba Fang Xiang Hua, Jiu Tu Lai Wang (Fig. 4). This mechanical doll's head would swing left and right as the mechanical idol writing Chinese characters. This is the related record about the import of automatic mechanical device into China. [7] Although the plastic shaping of automatic mechanical device had developed in ancient China, serious gaps already formed between the China and the Western in the expression of kinetic plastic shaping owing to the Qing Dynasty's policy of seclusion.

\section{DEVElopment OF KINETIC ART IN A.D.1900-1935}

\section{A. Futurism That Used Motion and Speed as Performance Theme}

When it entered to 20th century, artists of current modern art school started to feel unsatisfied about the traditional paintings and sculptures. Many artists who were interested in the motion device successively appeared. They were just like engineers who combine motors and gears in common research institute and tried to conceive artistic mechanical devices.

Influenced by symbolism and cubism and inspired by the photographers' art works recording the continuous motion of animals and figures in 1870s, artists who established futurism in Italy in 1909. They expressed the enthusiasm and desire for motion and speed. They stated in their declaration that "Kinetic theory of the universe must express the feeling of power. Motion and light destroy the essence of objects. We 
need to add a new form of beauty for the brilliant world. This is exactly the beauty of the speed" [8].

Futuristic artists praised and clearly accepted the value of the new era brought by mechanical civilization. The characteristics of this new era were mechanics, technology, and the corresponding motion, speed, strength, and competition. Such change made the world become further radiant and magnificent. So artists attempted to express what they felt about the new beauty of speed and motion derived from modern mechanics. They negated all the traditional art in the past and broke the past with the strongest approaches to express speed, technology, and futuristic [9].

Umberto Boccioni (A.D.1882-1916) was the most talented and creative artist and sculptor in futurism. In the artistic work: "Unique Forms of Continuity in Space", he expressed the speed and strength of the walking person in the wind in a highly tension form, just like the work casting by winds (Fig. 5). Manifesto of Futurist Sculpture proposed by Umberto Boccioni in 1912 challenged traditional enclosed sculpture. He reckoned that sculptures should emphasize on the expression of kinetics and atmospheres and advocated that all the materials could be used in sculptures without limitations.

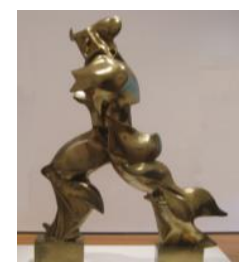

Fig. 5. Umberto Boccioni, unique forms of continuity in space, 1913 [10].

Though futurism came to a temporary pause after the death of Boccioni in 1916, artists still applied new materials produced by technology to produce novel art form under the reality that futurists confirmed mechanism. Use mechanics as the metaphor of real industrial society, which could be regarded as the changing power that could alter the expression forms of arts.

\section{B. Constructivism Adores Power Machinery and Technology}

Constructivism was the European artistic activity rose from Russia in 1919. Constructivism artists thought that the significance of the artistic creation should be emphasized on the structure of the space. So, they used simple and pure lines to against the traditional creation form and most of the works took sculpture as the themes. What was emphasized was the movement in the space rather than the senses of volumes and weights that once was the focus of non-traditional concepts of sculpture.

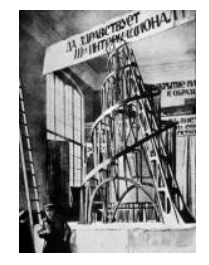

Fig. 6. V. Tatlin, monument to the third international, 1920 [11]

Vladimir Tatlin (A.D.1885-1953) could be regarded as the most suitable representative for this doctrine. The most famous work designed by Vladimir Tatlin was Monument to the Third International in 1920 (Fig. 6). Momentum includes architectures built with three different forms of glass house. The open structures and rotating walkways of the hard edge of spiral structure were manufactured with iron and glass, the new materials sufficient to be regarded as the representation of the $20^{\text {th }}$ century [12].

Gabo Naum could be regarded as the pioneer of modern kinetic art. He knew the knowledge of natural science and engineering and applied the principles of dynamics to complete lots of kinetic sculpture works. His kinetic plastic shaping works were not merely an aesthetic creation but also the result of technology research. In the work "Standing ware" designed in 1920, which was the first item that integrated dynamics into sculpture works [13]. For him, adding motion form in time was a kind of rhyme. As the type expressed in his works, he fully express such idea.

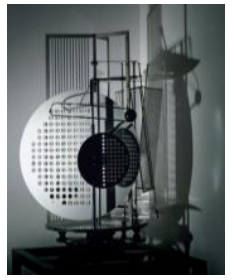

Fig. 7. Laszlo Moholy-Nagy, light space modulator, 1923-30 [14].

Another artist that posed far-reaching influences on the form of activity was exactly the person who implemented the preparation education of Bauhaus, Laszlo Moholy-Nagy (A.D.1895-1946). He performed historic result in the plastic shaping of kinetics. Light Space Modulator (Fig. 7), one of the famous works, has already become the milestone for the development of kinetic plastic shaping. He advocated that "we should replace the stationary principles in classical art with the moving principles of the universal lives. The actual method is to develop constitution in motion to replace stationary materials" [13].

\section{The Kinetic Art Courses in the Preparation Education of Bauhaus}

Bauhaus established in German in 1919 was the origin for building up modern design education. In the beginning of the establishment of school, school faculty Johannes Itten (A.D.1888-1967) thought that the school buildings were incomplete and the equipment was insufficient. So he proposed the suggestion to principal, Walter Gropius (A.D.1883-1969), about starting preparation education courses in the temporary classrooms to solve the difficulties in teaching. Unpredictably, this temporarily suggested preparation education courses nowadays became the model for basic design education. He once explained that "the main purpose of this course was to guide students' creating abilities and allowed them to become more familiar with each type of natural material. Also, students were expected to understand all the essential and basic principles for all the creating behaviors in visual arts".

In 1923, the provision of professors and teachers were then assigned to Josef Albers (1888-1976) and Laszlo Moholy-Nagy. In this time, the course time period was elongated to one year and the contents of the courses were 
also altered. The education goals were modified and shown below [15]:

- Being familiar with various materials and tools.

- Researching the Nature with various methods and further learning the basic methods and elements for plastic shaping.

- Learning the knowledge about the mathematics, mechanics, physics, chemistry, and etc. that may be essential for plastic shaping.

The previous 2 items roughly continued the teaching objectives in Itten time period. Nonetheless, the 3rd item of the goal clearly revealed that the necessities for science knowledge had highly increased, especially for the fundamental science related to kinetic art such as mathematics, mechanics, and physics. For the workers in design field, this is one kind of cross-field learning, which could essentially help to develop creativities and to activate thinking abilities [16].

\section{Satire on Visual Ambiguity-Dadaism}

Dadaism has been regarded as the idol destroyer of the century. Due to the weariness of the disturbance and tension of World War I and the discontent with the stifling standards that traditional values held towards artistic tastes and literary aesthetics, Dadaists denied fixed and stiff traditional values. However, what surprised people was Dadaism's attitude that was concerned with machinery.

In Dadaism, Duchamp's works were directly related to motions, which were an important factor in his creative perspective. What interested him the most was the change of forms [17]. Duchamp was also the first artist who noticed the effect of kinesthesia. In 1913, he created his first "ready-mades" work "Bicycle Wheel"-a work involving the installation of a bicycle wheel in a round stool. Entitled as "Mobile" [18], the work was a beautiful decoration.

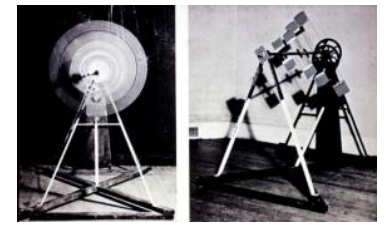

Fig. 8. Marcel Duchamp, rotary glass plates, 1920 [19].

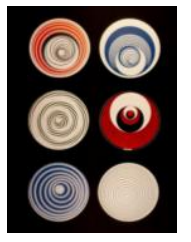

Fig. 9. Marcel Duchamp, Rotoreliefs, 1935 [19].

Duchamp later created a series of dynamic works powered by motors. For example, "Rotary Glass Plates" (Fig. 8) presented in 1920 was a work where five rectangular glass plates of different lengths with equidistant painted curves were installed separately in different distances on a revolving spindle. When the motor was on, the glass plate began spinning. As the spinning speed increased, the individual shape of each glass plate disappeared and the painted curves created a visual illusion similar to concentric circles. In terms of vision, individual shapes disappeared and a new visual motion shape was created. Duchamp attempted to use the effect of visual illusion created by the shapes in motion to have a satire on the momentum vision that knew the inexistence of concentric circles, instead of pursuing the joy of motions.

Between 1925 and 1935, Duchamp presented a series of works featuring Precise Optics, such as "Rotary Demisphere", "Anemic Cinema", and "Rotoreliefs" (Fig. 9), where Duchamp used the form of motor spinning to drive round plates with dynamic patterns, creating dizziness like a spiral whirlpool and illusionary spatial vision because of the visual response to physiological perception. "Rotoreliefs", in particular, used the same principle as the three-dimensional motion effect. Although the relationship between "Rotoreliefts" and Musatti's research remained inconclusive, Duchamp announced that it was his discovery and that it was an alternative to present scientific phenomenon [20], [21]. This showed that psychologists and artists were all highly interested in this issue. Duchamp's counterrevolution against traditional artistic tastes and denial of existing and fixed aesthetic standards signifies that new artistic game rules and ideological reformations have unveiled [22], which profoundly affect subsequent artistic performances.

\section{Development of Kinetic ART In A.D.1935-1970}

\section{A. Kinetic Art That Features Real Dynamics}

Kinetic art integrates motion into artistic works to create dynamic images of temporality and process in "space"-dynamic, split, and multi-spatial. [18] Dynamics becomes the major content, while the structural forms of works become secondary. What viewers appreciate is no longer work forms, but the motions in time and space. It could be divided into three types based on motions in works. The first type is the motion generated by natural forces such as wind and water. The second type is the motion effect created by changes of viewpoint as the reviewer moves. The third one refers to the use of motor drivers or artificial forces to make shapes generate motions [23].

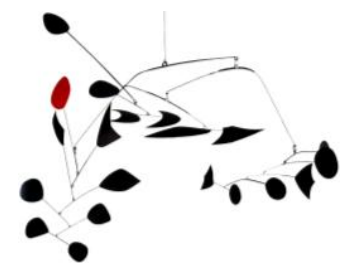

Fig. 10. Alexander Calder, Rouge Triomphant, 1963 [24].

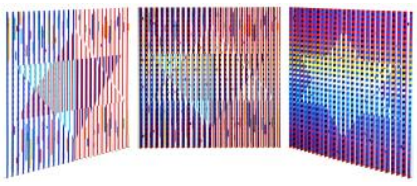

Fig. 11. Yaacov Agam, Star of David, 1983 [25].

Alexander Calder (A.D.1898-1976) was the iconic artist who used natural forces as the designing presentation, who always took delight in demonstrating motions. Calder developed "Mobile" (Fig. 10), a random dynamic form generated by wind. The concept of balance is applied to the 
series of works, where mobile steel leaves are attached to steel wires hung on the ceiling or on the tripod. When wind blows, these steel leaves are swaying gently in the wind.

Yaacov Agam (A.D.1928-) was the iconic artist who used changes of viewpoints as the designing presentation (Fig. 11) This type of works do not include real motions; instead, changes of viewpoints are created as reviewer moves, resulting in visual illusion created by the shapes in motion. The third one refers to the use of artificial forces to make shapes generate motions (mainly using mechanical devices as the motive power).

J. Tinguely (A.D.1925-1991), although used artificial powers, disregarded the correctness of machinery and the features of regularity. Tinguely developed a Meta mechanical skill, creating works of irregular and abrupt motions, such as Homage to New York presented in MOMA in the1960s. It was a self-destructing mechanical sculpture that included eight electronic closed-loops, scrap irons, a bicycle wheel, a player piano, and numerous components. Driven by motors, the giant sculpture whirled back and forth and made a harsh noise (Fig. 12). Tinguely demonstrated technological wrongness and absurdity via the absurd self-destruction of the mechanical sculpture, harsh noises, and consumption of the object.

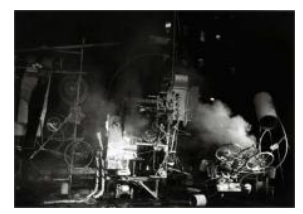

Fig. 12. J. Tinguely, homage to New York, 1960 [26].

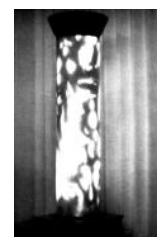

Fig. 13. Kinetic column Lumidyne system, 1961 [27].

Although artists in this period knew very well how to use mechanical devices for creation, mechanical device control inter related to the expression of motion aesthetics in works remained scarce. It was not until American mathematician Norbert Wiener (A.D.1894-1964) published "Cybernetics: Or Control and Communication in the Animal and the Machine" in 1947 did increasingly complicated mechanical operation have epoch-making advancement, which played an important role in the enhancement of stability and accuracy of control as well as the development of life and technology.

Undoubtedly, Frank Malina's (A.D.1912-1981) "Leonardo" specializing in art and technology since 1968 made the most significant contribution to photoelectric dynamic forms. Malina published numerous articles and theoretical inquiries into fields of science, technology, and art He has also been engaged in kinetic art creation since 1955. His works mainly used the swirls of mirrors and metals to reflect lights and created kaleidoscopic effect of lights and shadows [28]. For example, in "Kinetic Column Lumidyne System" (Fig. 13) in 1961, the lighting system in a translucent column changed as the machine rotated, with lights of different forms reflecting on the surface of the column and creating a magnificent artwork.

The relationship between kinetic art and science is unprecedented. Artists not only take mechanical power devices as a means of art, but also regard modern scientific technologies such as light and electricity as source materials for artistic creations. The application of new technological materials enables artists to create numerous new object dynamics and charming images.

\section{B. Optical Art Where Visual Perception Participates in Dynamic Form}

factors and use their eyes to sense and perceive works. Optical art emphasizes photoelectric visual expression, an abstract painting [29] focusing on visual illusions. In fact, this kind of painting makes the brain to produce wrong information and subsequent recognition of visual illusion through the retina. Just as William Seitz stated that optical art was the contributor to perceptual responses, whose powerful features generated visual illusions and hallucination in viewers' eyes or minds, and that optical art could be regarded as a type of art that explored basic and important illusions, basic concepts of plane or three-dimensional works of optical art [30]. Since viewers actively interact with works, relevant visual perceptions, such as changes of viewpoints, sizes of shapes, distance relationships, the fusion of colors, and motion parallax, are important means of expression.

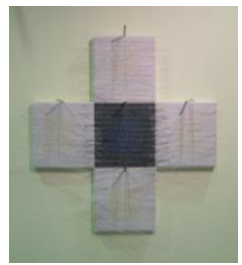

Fig. 14. Jesus Rafael Soto, Cruz cobalto y limon, 1975 [31].

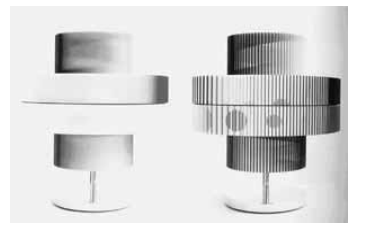

Fig. 15. Yaacov Agam, Remembrance and Growth, 1969 [32].

Creations based on visual perception as well as kinetic art are closely related to motions, in which Jesus Rafael Soto (A.D.1923-2005) and Yaacov Agam are regarded as the representatives. Soto's works used wires as the basic structure. The crisscross and interference effects among wires or between wires and planes created an amazing dynamic effect (Fig. 14). This kind of works does not contain a lot of dynamic changes. The whole dynamic change is presented to the retina, creating motion in a static situation. Yaacov Agam included dynamics and time into his creations and used the angle relationship among planes to create the fusion of colors (Fig. 15), not only diversifying the color expressions but also continuously changing the forms.

The analysis of works of the two artists shows that there are a lot in common between the two, where interactivity between works and viewers that makes artistic expression more vivid and interesting is created when viewers walked 
and looked at works or moved on all sides. Since their works do not create real motions and images of motion or visual illusions are created by changes of viewpoints when viewers move, this kind of expression where movement of viewpoints are created when viewers move is an important participatory and interactive artistic expression.

\section{DeVElopment of Kinetic ART AFTER A.D.1970}

\section{A. Electronic Technology Art that Expands Dynamic Forms}

After World War II, the rapid development and evolvement of electronic technology and techniques led to the expansion of dynamic forms, whose core creation was the computer invented in 1946. Computers are capable of processing, solving, and synthesizing complicated information, enabling the combination of dynamic forms and electronic technology to reach an unprecedented level. In addition, basic concepts and theories related to computer information processing, such as Norbert Wiener's (A.D.1894-1964) Cybernetics, Claude Elwood Shannon's (A.D.1916-2001) information theory, digital computer and digital circuit design theory, and John Von Neumann's (A.D.1903-1957) computer science, allowed artists to predominate over the use of tools for creation and expressions as well as contents of dynamic forms based on new electronic technologies and theories.

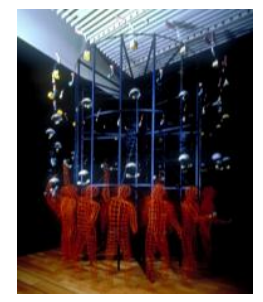

Fig. 16. Gregory Barsamian, Juggler, 1997 [33].

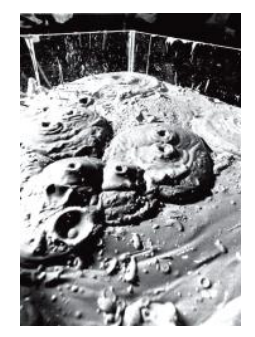

Fig. 17. Robert Rauschenberg, Mud-Muse, 1970 [34].

Gregory Barsamian (A.D.1953-) combined a high-speed stroboscopic device (Fig 16) with all kinds of vertical and horizontal movements to create vivid three-dimensional animations. The high-speed flashlight emitted from stroboscopic device allowed viewers to see instant images, leaving special effects of ever-changing forms on viewers' vision and creating illusions between reality and fantasy with the changes from conscious images to real images. In "Mud-Muse" (Fig. 17), Robert Rauschenberg (A.D.1925-2008) filled a rectangular container with industrial mud, with outlets of barometric valves scattering over the bottom of the rectangular container. Prerecorded sounds of waves, music and gears as well as sounds collected by on-site hidden microphones drove barometric valves and proceeded to control the mud in the rectangular container, creating the effect of mud churning in volcano eruptions.

Electronic technology and techniques have been rather highly-developed, whose development is not only a means and skill to expand artistic boundary but also a method and medium of form expression. Therefore, technological elements could not be withdrawn from works. Technology and art share the same status. To kinetic art that has developed so far, art relies on technology and develops a coexistent relationship with technology, thus realizing creative application and idea expression. In the meantime, information structures, procedural principles, and control feedbacks emphasized in electronic technology also exist in artists' creative thinking, making the cooperative relationship between kinetic art and technology even more important than before.

\section{B. Interactive Art Where Viewers Get Involved in Artistic Creation}

Compared with other expression forms of other art schools, modern technology art possesses three unheard-of characteristics: visual effect, artistic modality, and artistic interactivity [35]. Previous artistic expressions mainly focused on artists' personal subjective perceptions, and viewers could only feel the works via unidirectional "seeing". However, current advancement of electronic technology has yielded an interactive expression between kinetic art and viewers.

In addition to visual expressions that interactivity of modern technology art puts emphasis on, artists and viewers use sensory touches to make works react. Meanwhile, elements such as visual effects, motions, light, and sounds generate direct feedback. Reactions as the result of viewers' contact with works make viewers realize the joy of discovery and creativity via mutual interaction.

After Norbert Wiener proposed Cybernetics in 1947, artists found a new possibility between control and interaction. The theme of the Cybernetic serendipity, the earliest international exhibition that combined computer and art held in London in 1968, were the meeting and discovery of body and electronics, indicating artists' concerns about interaction. Works of kinetic art by subsequent artistic groups such as Group Zero, Gruppo T, Gruppo $\mathrm{N}$ and EAT (Experiments in Art \& Technology) were created on the premise of interactive relationships, with light, sound, and temperature in the exterior environment acting as the sensory mechanism that captured responses and actions.

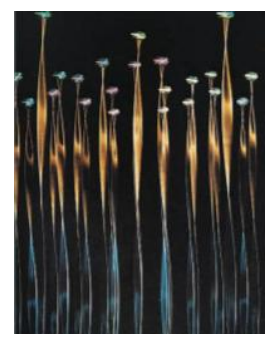

Fig. 18. Wer-Ying Tsai, Double Diffraction, 1971 [36].

Wen-Ying Tsai (A.D.1928-2013) has kept creating the series of Cybernetic Sculpture (Fig. 18), where he integrated 
Wiener's Cybernetics and works were amazingly bestowed with nervous tissue and thinking ability with the use of stainless steel, fiberglass, oscillator, motor, stroboscopic device, feedback sensor and computer control system equipped with artificial intelligence. Tsai's works have three characteristics: 1) Using hidden oscillator to create resonant vibration, which creates sine waves upon reaching the stainless steel pole. 2) Using stroboscopic device to make waves more clearly detected and change the luminous circle of stroboscopic device to create wave changes. 3) Instead of manual operation, the circles are changed with the use of voice-activated device to activate the frequency of oscillator or with the use of viewers' sounds or claps to control changes of frequency. Therefore, Tsai's works could be classified as "voice-activated kinetic art".

\section{CONCLUSION}

Through reviewing the literature, we can have a complete rethink of the existing model and present a new form. According to the literature review, the study summarizes the following conclusions:

\section{A. The Evolution of Kinetic Art Are Gradually Turned from Living Entertainment to Art Fields}

The developments of kinetic art before the $20^{\text {th }}$ century were meant to make life more convenient and efficient, especially in the significant points about elevating the human activity. Many inventions about kinetic art thus emerged.

As the coming of the $20^{\text {th }}$ century, kinetic art gradually turned from living entertainment to art fields. In that time period, artists felt unsatisfied on the traditional paintings and sculptures and started to think about how to express the actual motion on the artistic works. Futurism could only have one form of kinetic expression and no actual motion was produced. Constructivism expresses active attitude towards the applications of actual motion on sculpture works, which advocated that "actual motion" should be important aesthetic element for artistic works. So the earliest kinetic art that introduced actual motions to the works was created and the dimension of time was successfully added to the artistic works.

\section{B. Technology Exists in Creative Thinking}

The integration of Kinetic Art and science will propel Kinetic Art representation to an unprecedented state of prosperity. Not only light, electricity, and various science and technology can become the materials for Kinetic Art representation, different forms of power source can also be used as the means of Kinetic Art representation, to develop the Kinetic Art representation with new kind of state of movement. In this case, the movement state becomes the main content of the representation, the structure of the work ends up being the secondary. Given where Kinetic Art is at today, the influence of Kinetic Art can be said is extremely far-reaching.

The electronic-technical art of the later part of the 20th century, because of the establishment of related information soft / hardware and scientific theory, has enabled Kinetic Art creative molding's creation to achieve an unprecedented development. It enables artists to guide both Kinetic Art's form and content, and this also enables the demonstration of creativity and ideas. At the same time, electronic technology has its emphases on information structuring, programming principles and feedback. These are all encapsulated by Kinetic Art creative molding, which reveals the fact that Kinetic Art molding's co-operative relation with technology has been more important than ever before. On the other hand, Interactive Art enables Kinetic Art molding to transform again, allowing Kinetic Art molding to generate interactive creations, changing the piece's content, structure and the way it is being presented through the audiences' eyes. This means that the audiences' experience, sensation and feedback become part of the piece's meaning.

\section{Bauhaus Established the Status of Kinetic Art in Plastic Shaping Design Education}

As the origin of modern design education, Bauhaus started to promote the education route of "combination of aesthetics and science technology." In addition to reveal that the design of the art should be combined to science knowledge and technology, the related basic science and significance of kinetic art was also established. When Bauhaus was planning the preparation education, there was a goal to systemize the education of kinetic art. Via the systematic plastic shaping education about "motion", kinetic art thus became the research objects and directions for plastic shaping elements.

\section{Kinetic Art Is the Indispensable Manifestation Pattern in the Education of Modern Design}

The design education in the past seldom talked about the related theories and technologies of kinetic arts. This caused new-generation designer to become lack of the capacity to think and construct the kinetic shaping expression. If consider from the angle of cultivating new-generation designers, cross-field integration and learning must be emphasized in design education.

In the creating expression of modern design, adding high-technology-related form to works is becoming more and more common. So, listing kinetic art into the teaching courses of design education could allow students to understand the techniques and methods of each kinetic art and enable the application of practical designs and creation. In the future, this will form a trend in design education.

\section{E. Kinetic Art Will Drive the Development of New Vision Fields}

Kinetic art combining science and technology to show the status of the movement breaks restrictions of plane and stereo space in the past in shaping fields. Creative thinking of shaping was only limited in 3D static visual performance previously. Today, Kinetic Art has gone beyond such scope, dispreading toward new technology with scientific principles, and become a new visual field on the performance of shaping. In the visual fields cultivated by technology and media, it shows new performance. Since technology is changing rapidly, manifestations also need to be developed with continuous development and improvement of various. Under such complementary, a variety of creation of Kinetic Art has been developed continuously, not only leading to unexpected 
harvests in visual arts and design but also enhancing human's new experience in the visual senses.

\section{F. Kinetic Art Is Leading by High Technology and Developing in Dynamic Illusion Effect}

The works of Kinetic Art are considered the combination of technology and art, especially in the works that are merged with new scientific technique and art form; the creating field of Kinetic Art is expanded as well. Particularly the phenomenon which adopts Dadaism and Optical Art and that is focusing on "Movement Awareness". After being combined efficaciously with the visional awareness psychoanalytic axiom, this kind of visional dynamic illusion which is in the process of movement shows the sense of sight more about "Motion", and enhance the charm in modeling of itself. With the coalescence of various technique and materials and by the chance of experiencing the effect of new style, it cultivates the arrangement of beauty and the feel for Kinetic Art in order to discover the possibility of the expression of its style. The movement variation controlled by computer system or the sensor to sense the sound, light, temperature and etc. are getting much more, especially with the promotion of computer technology and the application in Multimedia. The purpose that Kinetic Art integrates designing emerges greatly in every exhibiting occasion. As the promotion in high technology result, we can expect the performance and the features of style will be changing gradually, and developed long lastingly.

\section{G. The Performance of Kinetic Art Will Combine Interaction and Participation}

Through interaction between viewer and work of Kinetic Art, when such work can be freely controlled by viewer's feeling or awareness, it allows the new artistic taste and fun experience of such work to be brought out. Therefore, in today's rapid development of computer technology and popularization, when creating interactive Kinetic Art works, creator must think about how to keep both interactivity and participation in consideration, and then through fun factor to enhance the entire Kinetic Art concept. As science and technology are growing at rapid pace, so is interactive Kinetic Art. How to show its artistic quality above technology and design characteristics above commercial value is what Kinetic Art creator needs to consider.

\section{REFERENCES}

[1] S. Tachikawa and A. Takayanagi, Trick, Tokyo: Kawade Shobo Shinsha, 1987.

[2] S. Kuwabara, Trick Encyclopedia, Tokyo: Chikuma Shobo, 1998.

[3] A. Au and J. Yeh. (March 2014). Ctesibius. [Online] Available: http://alexandrias.tripod.com/ctesibius.htm

[4] P. James and N. Thorpe, Records of the Inventions in the Ancient World in Figures, Taipei: Shi Chao Publishing Ltd, 2002.

[5] BBC. (March 2014). Automa-Bambino Scrittore: Uno Straordinario Antenato dei Computer. [Online] Available: http://www.link2universe.net/2013-11-07/automa-bambino-scrittore-u no-straordinario-antenato-dei-computer/

[6] X.-L. Guan, 200 Watches you Should Know, Taipei: Artist Press, 2007.

[7] J,-B. Lin, C.-H. Luo, C.-Y. Cho, and Q.-L. Chen, The Robot World, Taipei: Yinhoo Ltd, 1986.

[8] J.-C. Wu at el., A World History of Art, Taipei: Wooden Horse Culture Enterprise Co., Ltd, 2001.

[9] L. Gowing, J. Boardman, B. Gray, N. Lynton, R. Pickvance, J. Steer, G. Zarnecki, and M. Evans, The Encyclopedia of Visual Art, London: Encyclopaedia Britannica International, Ltd, 1983.
[10] M. Gerhardus and D. Gerhardus, Cubism and Futurism, New York: E. P. Dutton, 1979.

[11] T. Choisis, Art et Poesie Russes, Paris: Troels Andersen, 1979.

[12] Y. Nakahara, A Great Invention Story, Tokyo: Art Publisher, 1975.

[13] T. Ito, Mechanical Art Theory-Another 20th Century Art History, Tokyo: Iwanami Bookstore, 1991.

[14] T. Ito, Bauhaus Revisited, Ten plus one, 17. Tokyo: INAX Publishing, 1999.

[15] P.-C. Lin, Fundamental Design Education, Taipei: Artist Publisher, 1990.

[16] H. Miyajima, Design of Transition to Basic Education and the Birth of the Pre-Education, vol. 3, pp. 107, 1968.

[17] G. W. Rickey, "The morphology of movement: a study of kinetic art," Art Journal, vol. 22, pp. 220-231, 1963.

[18] S. Zeki, Inner Vision: An Exploration of Art and the Brain, London: Oxford University Press, 2000.

[19] Mainichi Newspapers, 100th Birthday Kanonen-Man Ray Exhibition, Tokyo: Mainichi Shimbun, 1999.

[20] Rosalind Krauss, The IMPLUSE to See in Vision and Visuality, Foster, Hal, ed. Seattle: Bay Press, 1988.

[21] H. Miyauchi, "Marcel Duchamp "anemic cinema" (1925-26) about the action and the sexuality of in physicality," F-GENS magazine: Ochanomizu University 21st Century COE Program "Frontier of Gender Studies", vol. 10, pp. 198-205, 2008.

[22] P. Cabanne, Paris Vous Regarde, Paris: P. Bordas, 1988.

[23] Y. Tomoya, Art Annual Report of University of Tsukuba: Kinetic-Art. Tsukuba: Department of Arts of University of Tsukuba, 1985.

[24] J. Lipman, Alexander Calder and His Magical Mobiles, Manchester: Hudson Hills Press, 1981.

[25] Masterworks Fine Art. (March 2014). Star of David. [Online]. Available: http://www.masterworksfineart.com/inventory/agam?msg=legacy

[26] F. Popper, Art of Electronic Age, London: Thames \& Hudson, 1993.

[27] Archive of Affinities. [March 2014]. Kinetic Column Lumidyne System. [Online]. Available: http://archiveofaffinities.tumblr.com/post/18194766400/frank-j-malin a-kinetic-column-1961

[28] J. Reichardt, Cybernetic Serendipity: the Computer and the Arts, London: Studio International, 1968.

[29] Y. Nakahara, Encyclopedia of Modern Art, Tokyo: Art Publisher, 1988.

[30] T.-C. Yu, "A study and experiment in the visual illusion of shape and color: take the work of victor vasarely as the example," M. F. A. thesis, Dept. Visual Communication Design., Kun Shan Univ., Tainan, Taiwan, 2005.

[31] M. Joray, Soto, Neuchâtel: Griffon, 1984.

[32] Asahi Shimbun Tokyo Head Planning first compilation, Father of Modern Art: Kinetic- Agamu Exhibition Works, Tokyo: Asahi shinbunsha, 1989.

[33] ICC Collection, Juggler/Gregory barsamian, Inter Communication, vol. 21, Tokyo: NTT Publishing, 1997.

[34] Y.-C. Tseng, "An Absent History: From Arts and Technology to Digital Arts," Journal of Aesthetics Education, vol. 169, pp. 12- 21, 2013.

[35] H. Mitsui, Kinetic-Art, Tokyo: Seidosha, 1994.

[36] Chunichi Shimbun Edition, The 2nd International Biennale in Nagoya-ARTEC'91, Tokyo: Chunichi Shimbun, 1991.

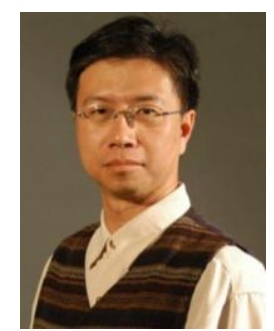

Guang-Dah Chen was born in Penghu, Taiwan in 1964. He won the M.A. in design at Univ. of Tsukuba, Japan and also achieved Ph.D. in design at National Taiwan Univ. of Science of Technology, Taiwan. Dr. Chen has worked for Dept. of Visual Communication Design at NTUA as an associate professor and chairman of Center for Teaching and Learning Development (2010-2011), an associate professor and chairman of Dept. of Visual Communication Design at Kun Shan Univ. (2002-2010) and chairman in Taiwan Society of Basic Design and Art (2001-2006). Now he serves as an associate professor in National Yunlin Univ. of Science and Technology, Taiwan and representative of Asia Network Beyond Design, Taiwan and a honorary chairman in Taiwan Society of Basic Design and Art. He research is focused on interdisciplinary design in basic design and art combined with technology and art. Dr. Chen specializes in basic design and art, light construction, motion construction, hi-tech art, digital context industries, visual communication design, interdisciplinary design etc. 


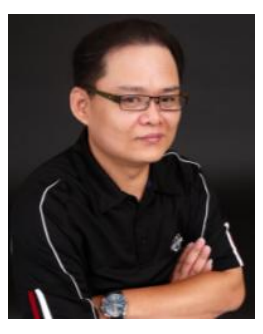

Chih-Wei Lin was born in Changhua, Taiwan in 1971. He won the M.F.A at Kun Shan Univ., Taiwan. Now he is a Ph.D. student at the Graduate School of Design, National Yunlin Univ. of Science and Technology, Taiwan, creative director in Guan-Yi Advertising Design, director at Tainan Art \& Design Association, member at Taiwan Society of Basic Design and Art, part-time lecturer at Dept. of Visual Communication Design, Kun Shan Univ., part-time lecturer at Dept. of Culture and Creative Enterprise Management, Nanhua Univ., part-time lecturer at Dept. of Cultural Activities Development, Chia Nan Univ. of Pharmacy and Science. His research is focused on interdisciplinary design in basic design and art combined with technology and art. Lin specializes in basic design and art, motion construction, visual communication sesign, advertising design, package design, visual identity design, poster sesign etc.

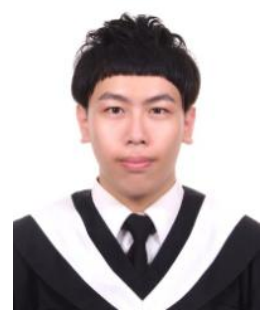

Hsi-Wen Fan was born in Taichung, Taiwan in 1991. He won the bachelor degree at Kun Shan Univ., Taiwan. Now he is a graduate student at the Dept. of Digital Media Design, National Yunlin Univ. of Science and Technology, Taiwan, studen member at Taiwan Society of Basic Design and Art, student member in Taiwan Society of Basic Design and Art, student member at Taiwan Insititute of Kansei. His research is focused on basic design and art combined with technology pendulum photo and art history. Fan specializes in basic design and art, light construction, aesthetics, visual culture, color management, and curriculum \& instruction. 